NOTAS Y RESÚMENES DE TRABAJOS DE INVESTIGACIÓN

\title{
DEMANDAS CIUDADANAS DESDE EL ASOCIACIONISMO VECINAL: UN EJEMPLO DE PARTICIPACIÓN EN LA CIUDAD DE ZARAGOZA
}

\author{
Elisa Esteban Carbonell \\ Unión Vecinal Cesaraugusta
}

El "Estudio de necesidades de la ciudad de Zaragoza. Diagnóstico del año 2020" ha tenido como objetivo recoger las diferentes necesidades y/o demandas detectadas por las diferentes asociaciones vecinales que aglutina la Unión Vecinal Cesaraugusta en materia de urbanismo e infraestructuras de la ciudad. Por su configuración, la Unión Vecinal tiene una visión del conjunto de la ciudad, por lo que las acciones van encaminadas a satisfacer las necesidades de toda Zaragoza. En la línea de dar respuesta a las necesidades de las asociaciones vecinales, la Unión Vecinal lleva tiempo trabajando, recogiendo las demandas planteadas por las asociaciones y trasladándolas a las administraciones competentes.

En total, 27 asociaciones del total de 32 que componen la Unión Vecinal Cesaraugusta han participado en este estudio y han identificado necesidades a través de la cumplimentación de un cuestionario diseñado ad hoc de carácter abierto, donde se ha dado una referencia espacial a cada necesidad identificada. El cuestionario se ha organizado en torno a ocho dimensiones: alumbrado; accesibilidad; señalización; servicios, equipamientos y/o recursos; movilidad; limpieza; medio ambiente y sostenibilidad; y otros. Junto al cuestionario, las diferentes asociaciones han aportado también fotografías para acompañar las distintas necesidades detectadas. La recogida de la información comenzó en febrero de 2020 y fue interrumpida por la extraordinaria situación vivida por la pandemia de COVID-19. Se retomó y finalizó en el mes de junio de 2020.

El informe muestra por medio de gráficos los principales resultados, donde destacan las necesidades en las dimensiones de accesibilidad, movilidad, así como medio ambiente y sostenibilidad. Concretamente, por dimensiones, cabe señalar:

- 13 asociaciones han referenciado deficiencias en el alumbrado de sus respectos barrios y/o distritos. 
- El área de accesibilidad hace referencia al acceso a edificios públicos (rampas, ascensor), acceso en las vías públicas (rebaje bordillos, ancho de las aceras) y adecuación de las aceras, específicamente, baldosas levantadas, socavones, entre otras. El estudio revela que 12 asociaciones han identificado deficiencias en las aceras, seguido muy de cerca por los problemas identificados en el ancho de las aceras. Es decir, aceras que no permiten el paso a sillas de ruedas o carros de bebés.

- El área de señalización incluye deficiencias en la disposición de carteles, placas o señales que indiquen servicios de los distritos o barrios. Únicamente 6 asociaciones han identificado necesidades en esta área.

- Las necesidades del área de servicios, equipamientos y/o recursos se centran en dos aspectos: acondicionamiento y dotación. 13 asociaciones solicitan equipamientos en sus zonas al carecer de ellos, mientras que 6 asociaciones reclaman la mejora de los equipamientos ya existentes.

- El área de movilidad incluye incidencias en cuatro categorías: transporte, estacionamiento, velocidad e incidencias en la vía pública. Las necesidades en relación al transporte hacen referencia a falta de transporte público en determinados barrios, solicitud de recorridos alternativos, deficiencias en la frecuencia, entre otras. En el caso de las necesidades respecto al estacionamiento, éstas se refieren tanto a estacionamiento para vehículos, como para bicicletas o patinetes e incluyen fundamentalmente necesidades sobre falta de estacionamientos suficientes y, en algún caso, estacionamientos en mal estado de conservación. Por su parte, las necesidades en torno a la velocidad se centran principalmente es el exceso de velocidad o no respeto de los límites de velocidad establecidos. Por último, las incidencias en la vía pública recogen necesidades variadas que van desde la circulación de patinetes y bicicletas por las aceras hasta la falta de visibilidad en carriles bici o calzada causada por árboles o arbustos. 16 asociaciones han identificado necesidades en el transporte; a estas le siguen en el estacionamiento (demandas de creación de estacionamiento, provisión de plazas de estacionamiento regulado para residentes y comerciantes, o deficiencias en el estacionamiento de bicicletas).

- El área de limpieza incluye acumulación de suciedad y falta de contenedores (o papeleras). Las quejas en torno a deficiencias de limpieza son numerosas (14 asociaciones).

- En el área de medio ambiente y sostenibilidad, 17 asociaciones han identificado necesidades en parques y jardines (estado de la poda de árboles y/o escasez de zonas verdes). Asimismo, 10 asociaciones han reseñado la existencia de alcorques vacíos en sus zonas.

- La categoría otros ha estado abierta para identificar necesidades variadas que no pudieran incluirse en el resto de áreas. Entre ellas, 12 asociaciones han identificado deficiencias en el asfaltado de calles. 
Junto a estos datos de carácter general, el listado incluye un listado pormenorizado y organizado según dimensiones de análisis para los ocho distritos urbanos (Actur-Rey Fernando, Delicias, Casablanca, Casco Histórico, La Almozara, Oliver-Valdefierro, TorreroLa Paz, Universidad) y seis barrios rurales (Monzalbarba, Garrapinillos, La Cartuja Baja, Juslibol-El Zorongo, Casetas, Venta del Olivar) con representación en este estudio. Asimismo, para cada uno se presentan mapas donde se han geolocalizado las necesidades gracias a la herramienta de mapas colaborativos del Ayuntamiento de Zaragoza y que, desde este momento, se encuentran disponibles para ser consultados en la web municipal (Enlace: https://www.zaragoza.es/sede/portal/participacion/en-tu-barrio/mapasuvc) y abiertos para que cualquier persona dada de alta en la plataforma de Gobierno Abierto de la sede electrónica municipal pueda añadir contenido a los mapas existentes (Enlace: https://www.zaragoza.es/sede/servicio/mapa-colaborativo/?category=9).

Para facilitar su difusión y consulta, desde la Oficina Participación, Transparencia y Gobierno Abierto se han tratado los datos recogidos por la Unión Vecinal Cesaraugusta y se han presentado en mapas por distritos o barrios que pueden consultarse a pantalla completa modificando la escala de análisis. Destacan igualmente los distintos tipos de demanda a los que se les ha otorgado un símbolo diferente para facilitar la lectura de los mapas.

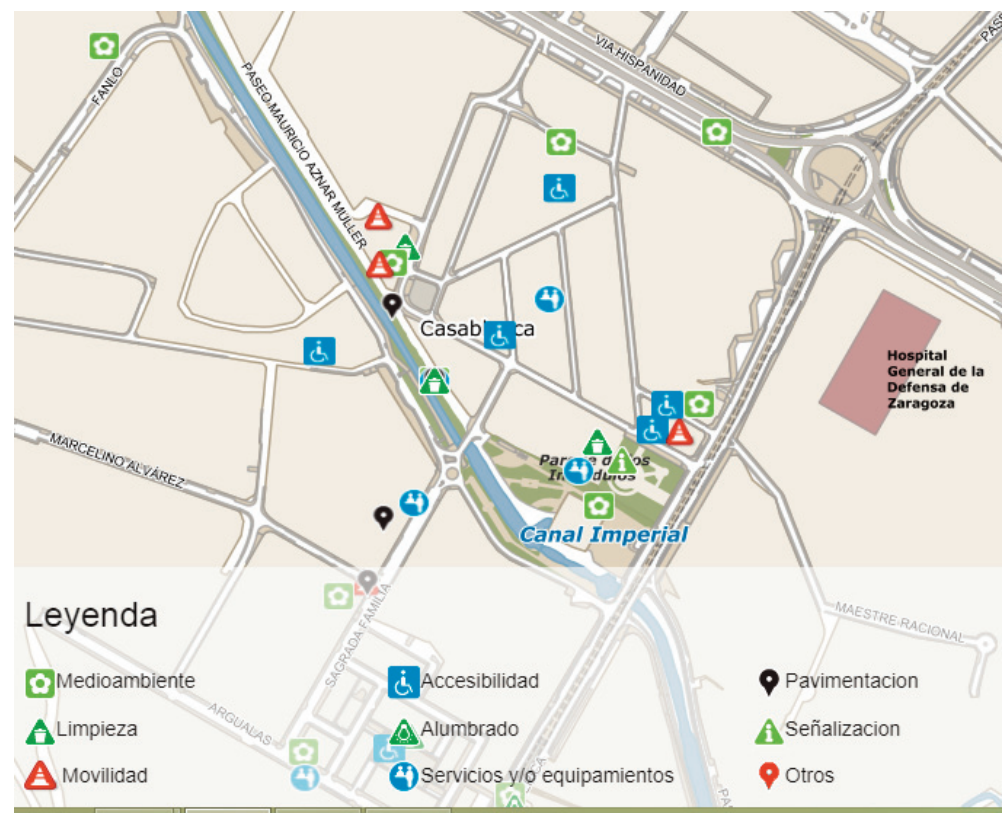

Figura 1. Mapa de Casablanca en la ciudad de Zaragoza.

Fuente: Gobierno Abierto-Ayuntamiento de Zaragoza. 
La figura 1 incluye algunas de las necesidades demandadas en el distrito de Casablanca junto a la leyenda que se acompaña para identificar los distintos tipos. Se ha creado una nueva categoría a la hora de realizar los mapas (pavimentación) por el número destacado de deficiencias en este ámbito.

La figura 2 muestra algunas necesidades detectadas en el distrito de Actur-Rey Fernando donde se identifican varias relativas a medio ambiente y sostenibilidad (verdes) y a movilidad (triángulo rojo).

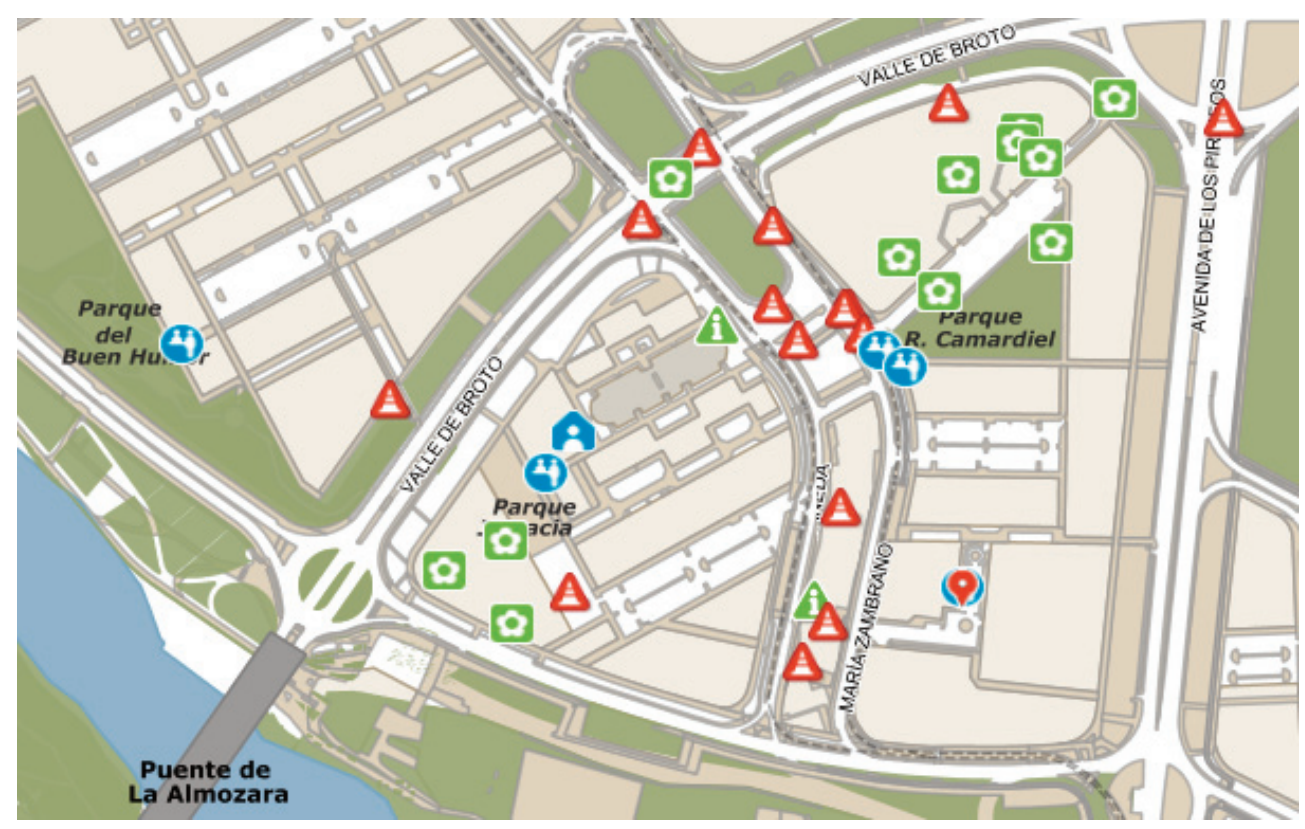

Figura 2. Mapa de Actur-Rey Fernando en la ciudad de Zaragoza.

Fuente: Gobierno Abierto-Ayuntamiento de Zaragoza.

La figura 3 muestra una imagen aportada por una asociación perteneciente al distrito Universidad. En este caso, en una necesidad de medio ambiente y sostenibilidad, específicamente, deficiencias en la poda se ha adjuntado una fotografía donde se describe de forma breve la necesidad y se identifica la asociación que ha referenciado el dato. El mapa permite ver la deficiencia al mismo tiempo que situarla geográficamente en la ciudad.

La figura 4 muestra otro ejemplo de necesidad identificado, en este caso, para dotar de mayor seguridad a los peatones en una infraestructura ciclista. 


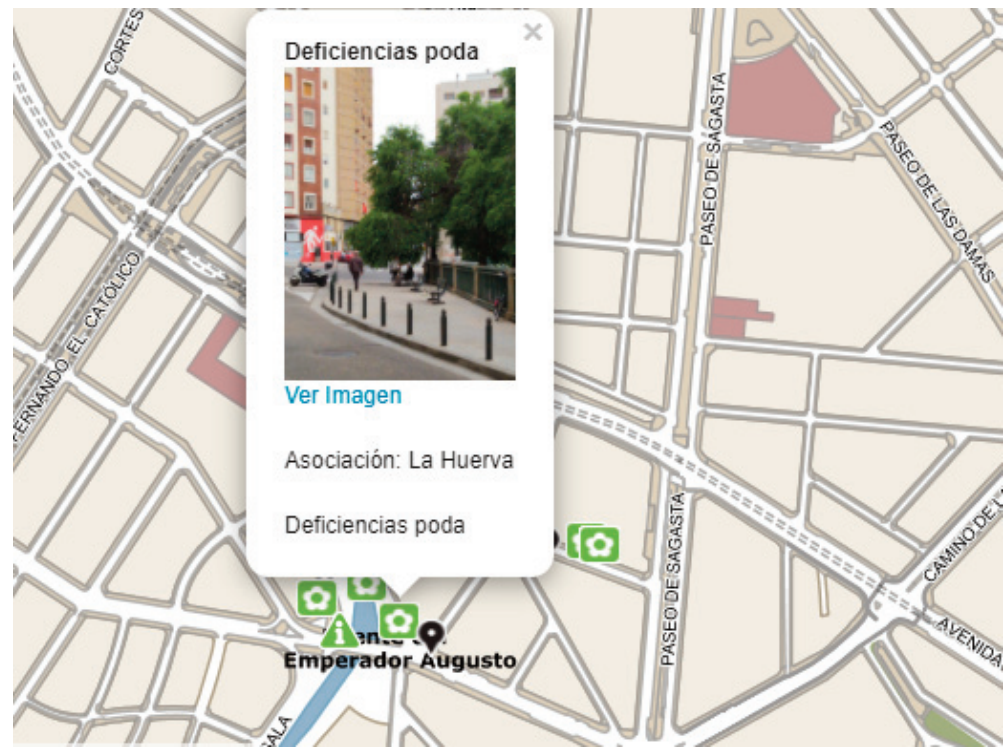

Figura 3. Mapa del distrito Universidad en la ciudad de Zaragoza.

Fuente: Gobierno Abierto-Ayuntamiento de Zaragoza.

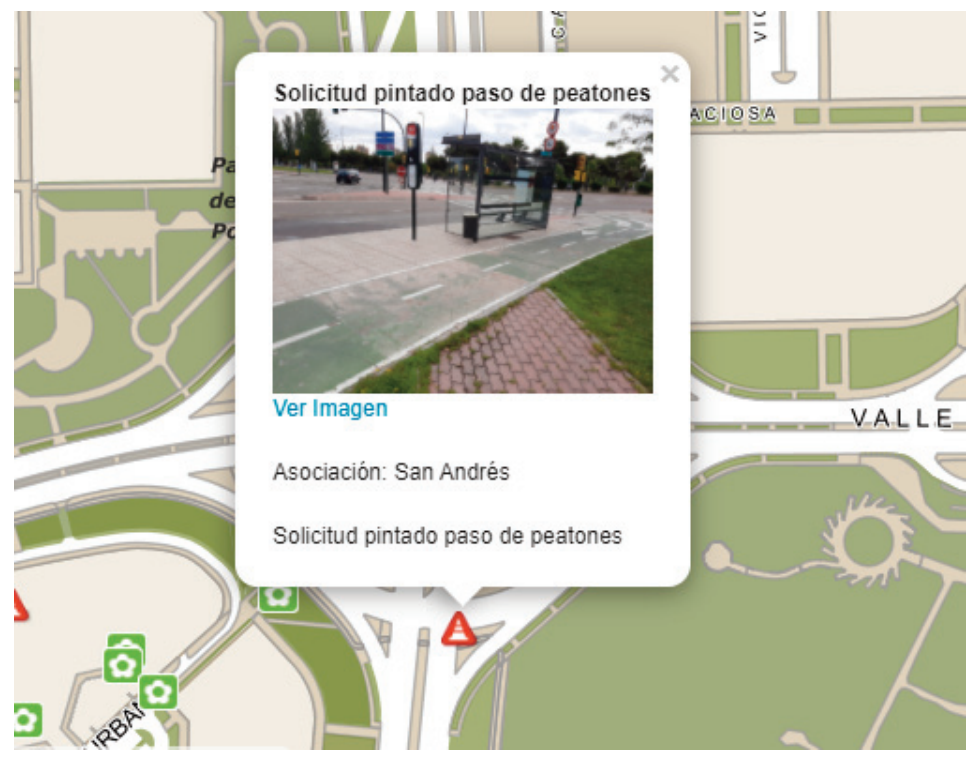

Figura 4. Mapa del distrito Actur-Rey Fernando.

Fuente: Gobierno Abierto-Ayuntamiento de Zaragoza. 
Más allá de los datos recogidos, el presente estudio es una radiografía de la ciudad en un momento concreto advirtiendo, por tanto, la posibilidad de que algunas de las necesidades que aquí se recogen hayan podido resolverse en el transcurso de estos meses.

En conclusión, este trabajo es un claro ejemplo de proceso participativo que ha contado con la colaboración de un número significativo de asociaciones. Por otra parte, pretende ser un estudio recurrente -con actualizaciones periódicas- y práctico, por lo que esperamos que sea tenido en cuenta por el equipo de gobierno para futuras actuaciones en la planificación de la ciudad.

\section{Bibliografía}

Ayuntamiento de Zaragoza (2020). Diagnóstico de necesidades y demandas de los barrios de Zaragoza. Recuperado de: https://www.zaragoza.es/sede/portal/participacion/en-tu-barrio/mapas-uvc

Unión Vecinal Cesaraugusta (2020). Nota de prensa. Recuperado de: https://unioncesaraugusta.org/nosotros/diagnostico-de-necesidades-y-demandas-de-los-barrios-de-zaragoza/ 